\title{
Prevalence of Antibiotic Resistant Bacteria in Ready to eat Food Sold by Street Vendors in Bangladesh
}

\author{
Sayed M. Nahidul-Islam
}

\section{ABSTRACT}

\begin{abstract}
Bangladesh has a vibrant street food culture, with easily available ready-toeat (RTE) foods. In this study, a total of 221 isolates were obtained from 141 Bangladeshi RTE food samples, such as fried, non-fried, and cooked foods; egg-, milk-, cereal-, and cream-based foods; pickles/achar; fruit; and RTE leaves, through culture on trypticase soy (for aerobic plate count), mannitol salt (MS for Staphylococcaceae), deoxycholate-hydrogen sulfide-lactose (DHL, for Enterobacteriaceae), and NaCl glycine Kim Goepfert agar (NGKG, for Bacillus cereus-like bacteria) agar plates. The aerobic plate counts ranged from undetectable to $8.5 \log \mathrm{CFU} / \mathrm{g}$. After enrichment with peptone water, contaminated bacteria detected on DHL, MS, and NGKG agar plates, from 77, 110, and 77 samples, respectively. Twenty out of 111 isolates on DHL agar, and 17 of 32 isolates on NGKG agar clearly showed resistance against three or more drugs. Through 16S ribosomal DNA sequencing analysis, six selected isolates from DHL agar were identified as Pseudomonas nitroreducens, Citrobacter braakii, Klebsiella pneumoniae subsp. pneumoniae, and Serratia marcescens. One selected isolate from NGKG agar was identified as Bacillus cereus-like bacteria. The results suggest that additional safety measures and regulations are necessary to ensure the quality and safety of the RTE foods in Bangladesh.
\end{abstract}

Keywords: antibiotic resistant bacteria, food safety, ready to eat food, street vendor.

\section{INTRODUCTION}

Bangladesh is one of the most densely populated countries in the world, and it has a vibrant street food culture, with ready-to-eat (RTE) foods, beverages, and snacks easily found at almost any time of the day [1]. The general Bangladeshi population's traditional eating habits are changing due to rapid urbanization [2]. Changing lifestyles, including an increasing number of women working outside the home and changes in family structures, encourage more people to consume RTE foods than home-cooked food, which was the standard practice in the last century [3]. There are 128 varieties of street foods found in Dhaka, Bangladesh, among which chotpoti, bhelpuri, samucha, jhalmuri, daalpuri, lassi, pakura, and halim are the most popular [4]. Traditionally RTE foods and beverages are produced at the commercial or household level; unfortunately, such food items are sold by grocery stores, department stores, vendors, and supermarkets without supervision by authorities [5]. Bangladesh has long been facing problems associated with microbiological contamination of various foods due to the lack of awareness on hygiene followed by the defective legislative action [6].

In developing countries, bacterial diarrhoea causes high mortality [7]. Controlling microorganisms is essential to addressing the microbial safety issues associated with RTE foods. The World Health Organization estimates that foodborne and waterborne diseases together globally kill approximately 2.2 million people annually, including 1.9 million children [8], [9]. However, in Bangladesh, a dependable assessment of the public health impact of food contamination is not available due to the absence of a regular monitoring system. Limited data from the International Centre for Diarrhoeal Disease Research, Bangladesh, indicates that 501 hospital visits for diarrhoea treatment per day were attributable to food- and waterborne illnesses [10]. Multi-drug resistant (MDR) bacterial infections are a public health problem worldwide [11]. It can be considered that multi-drug resistance genes of bacteria found in foods can be horizontally transferred to human gut bacteria, including opportunistic pathogens [12], [13]. Many researchers have reported the role of street foods as vectors of pathogenic bacterial transmission to humans [14]. Most studies focus on microbiological and hygiene quality; however, only few efforts have been made to identify antibiotic-resistant organisms, although the status of multi-drug resistance plays an important role in fighting foodborne pathogens [15], [16]. Several studies have assessed foodborne pathogens in RTE foods in other countries. For example, among 154 foodborne Staphylococcus aureus isolates analysed in Turkey, 39 (25.3\%) were found to be MDR [17]. In a study on vegetables collected in Switzerland, 78.3\% (47/60) of samples contained MDR extended-spectrum $\quad \beta$-lactamase-producing Enterobacteriaceae isolates [18]. In Bangladesh, some research teams have focused on the microbiological quality of RTE foods; however, few efforts have been made to determine antibiotic resistance levels and associated 
resistance mechanisms in these foods [19]. Therefore, in this study, to confirm the existence of multi-drug resistance and the potential contribution of food to the dissemination of antibiotic-resistant pathogens, various RTE foods (141 samples) were collected mainly from street vendors in the densely populated cities of Dhaka, Chittagong, and Cox's Bazar in Bangladesh. The level of multi-drug resistance of a total of 221 isolates was determined using classical disc diffusion assay, and the strains having high resistance against multiple drugs were selected and identified.

\section{MATERIALS AND METHODS}

\section{A. Collection of RTE Food Samples}

A total of 141 food samples (Table I) were collected from randomly selected vendors operating in Dhaka, Chittagong, and Cox's Bazar between June and December 2019. All samples were handled aseptically during transportation and kept in sterile containers until they were prepared for bacteriological analysis. The information of each sample is shown in Table I. The products were preserved in the refrigerator $\left(4^{\circ} \mathrm{C}\right)$, except for the RTE tobacco. Food product $\mathrm{pH}$ was measured using a $\mathrm{pH}$ meter (B-711 LAQUAtwin, Horiba, Kyoto, Japan), and salinity was measured with a salinity analyser (B-721 LAQUAtwin, Horiba).

\section{B. Aerobic Plate Counts}

A $3 \mathrm{~g}$ sample of each food was homogenised in $30 \mathrm{~mL}$ of phosphate-buffered saline (Nissui Pharmaceutical, Tokyo, Japan) containing $0.1 \%$ (w/v) agar. The serial diluted samples $(0.03 \mathrm{~mL})$ were plated on trypticase soy (TS) agar (Nippon Becton Dickinson, Tokyo, Japan) plates and incubated at $30{ }^{\circ} \mathrm{C}$ for isolation of aerobic bacteria. Plates of deoxycholate hydrogen sulfide lactose (DHL) agar (for Enterobacteriaceae, Eiken Chemical, Tokyo, Japan), mannitol salt (MS) agar (for Staphylococcaceae, Eiken Chemical, Tokyo, Japan), and NaCl-glycine Kim and
Goepfert (NGKG) agar (for Bacillus cereus-like bacteria, Nissui Pharmaceutical) were incubated at $30{ }^{\circ} \mathrm{C}(\mathrm{NGKG})$ or $37{ }^{\circ} \mathrm{C}$ (DHL, MS) for $24 \mathrm{~h}$ under aerobic conditions. Viable cell counts were calculated from the number of developed colonies.

\section{Isolation and Antibacterial Resistance Test}

Each sample ( $3 \mathrm{~g}$ ) was enriched at $37^{\circ} \mathrm{C}$ for $18 \mathrm{~h}$ using 30 $\mathrm{mL}$ of buffered peptone water (BPW, Nippon Becton Dickinson) and streaked on DHL, MS, and NGKG agar. After $24 \mathrm{~h}$ incubation, as described above, typical colonies from the plates were isolated. The susceptibility of the isolates to different antimicrobial agents was determined with the disc diffusion assay using 10 or 11 antibiotic discs: ciprofloxacin (CPFX, $5 \mu \mathrm{g}$ ), ampicillin (ABPC, $10 \mu \mathrm{g}$ ), fosfomycin (FOM, $50 \mu \mathrm{g}$ ), ofloxacin (OFLX, $5 \mu \mathrm{g}$ ), tetracycline (TC, $30 \mu \mathrm{g}$ ), gentamicin (GM, $10 \mu \mathrm{g}$ ), vancomycin (VCM, $30 \mu \mathrm{g}$ ), levofloxacin (LVFX, $5 \mu \mathrm{g}$ ), chloramphenicol (CP, $30 \mu \mathrm{g})$, trimethoprim/sulfamethoxazole (ST, $23.75 \mu \mathrm{g} / 1.25 \mu \mathrm{g}$ ), and cefoxitin (CFX for methicillin-resistant staphylococci, $30 \mu \mathrm{g}$ ) (BD Sensi-Disc ${ }^{\mathrm{TM}}$, Nippon Becton Dickinson) on MuellerHinton agar (Oxoid, Basingstoke, UK). The assay allows the determination of bacterial resistance to the antibiotic on the disc, based on the relative diameter of the zone of inhibition surrounding the disc. Briefly, isolated colonies were inoculated into the nutrient broth, incubated at $37{ }^{\circ} \mathrm{C}$ for 24 $\mathrm{h}$, and then spread $(0.1 \mathrm{~mL})$ on the test plates. The diameters of the inhibition zones (Fig. 2) were measured using precision callipers $24 \mathrm{~h}$ after incubation. The resistance was as resistance (R), intermediate resistance (IR), and susceptible (S) according to manual of the disk products and the British Society for Antimicrobial Chemotherapy (BSAC) standard disc susceptibility [20]. Additionally, among the R group, isolates that showed no clear zone were defined as no clear zone (NCZ).

TABLE I: VALUES OF PH AND SALINITY IN READY TO EAT (RTE) FOODS DISTRIBUTED IN BANGLADESH

\begin{tabular}{|c|c|c|c|c|}
\hline Groups & Sample name (number of samples) & $\begin{array}{l}\text { Samples/ } \\
\text { group }\end{array}$ & $\mathrm{pH}^{*}$ & $\begin{array}{l}\text { Salinity* } \\
(\%)\end{array}$ \\
\hline Cream-based food & $\begin{array}{l}\text { Cream bun (3), cream cake, layer cake, sandwich sponge cake, butter cake } \\
\text { (2) }\end{array}$ & 8 & $5.58 \pm 0.50$ & $0.90 \pm 0.27$ \\
\hline Egg-based food & Egg cake (3), egg alor chop, vanilla egg bun, custard cake & 6 & $5.24 \pm 0.32$ & $1.00 \pm 0.24$ \\
\hline Milk based food & $\begin{array}{l}\text { Lassi, matha, borhani, shandesh (2), dahi (3), laddu (2), shonpapri, modhu- } \\
\text { sandesh, doi-fuska }\end{array}$ & 13 & $5.14 \pm 1.10$ & $0.91 \pm 0.72$ \\
\hline Non fried dry food & $\begin{array}{l}\text { Toast, biscuit, dry cake (2), coconut fudge ball, pinuts cookies, vapa pitha } \\
\text { (4), patishapta pitha (2), chitoi pitha, taler pitha }\end{array}$ & 15 & $5.81 \pm 0.79$ & $1.05 \pm 0.25$ \\
\hline Fried dry food & $\begin{array}{l}\text { Fried pitha (3), jhal petiesh, coconut khaja, velpuri (2), singara, samosa } \\
\text { (2), nimki, piaju, anthon, egg chop }\end{array}$ & 14 & $5.44 \pm 0.61$ & $0.61 \pm 0.27$ \\
\hline Cooked food & $\begin{array}{l}\text { Payesh, suji/halwa (2), chicken roll (3), chicken samosa, chicken } \\
\text { sandwich, chotpoti (4), fuska (5), noodles, pizza, crab-jhal }\end{array}$ & 20 & $4.67 \pm 0.46$ & $1.18 \pm 0.42$ \\
\hline $\begin{array}{l}\text { Fruit juice and liquid } \\
\text { food }\end{array}$ & $\begin{array}{l}\text { Mango juice, basil seed juice (2), aloe vera juice, sugarcane juice (3), } \\
\text { shorbot, tetul juice (3), isabgol juice. }\end{array}$ & 12 & $4.54 \pm 0.85$ & $0.53 \pm 0.49$ \\
\hline Cereal based food & $\begin{array}{l}\text { Jilapi, pauruti, pantavaat, corn flakes, muri, jhal muri (3), puffed rice ball, } \\
\text { naan, jorda vaat }\end{array}$ & 11 & $5.64 \pm 0.87$ & $0.89 \pm 0.34$ \\
\hline Pickle/achar & $\begin{array}{l}\text { Boroi/kul chatni (9), mango achar (6), jam chatni (2), tamarind achar, } \\
\text { pinapple chatni, mix fruits achar, dates achar (3), kasundi, guava pickle }\end{array}$ & 25 & $3.86 \pm 0.99$ & $0.90 \pm 0.35$ \\
\hline RTE betel leaves & (paan) betel leaf with areca nut (8) & 8 & $4.53 \pm 0.29$ & $0.67 \pm 0.31$ \\
\hline \multirow[t]{2}{*}{ RTE tobacco } & $\begin{array}{l}\text { Swagat, kuber, zit, pan parag, pan masala (2), baba } 120 \text { plus, dilber, } \\
\text { special gul, supari }\end{array}$ & 9 & $7.98 \pm 0.98$ & $1.86 \pm 0.36$ \\
\hline & Total & 141 & & \\
\hline
\end{tabular}


TABLE II: Viable BACTERIa COUNT AND DETECTION WITH THE SELECTIVE AGAR PlateS WiTH ENRICHMENT IN THE RTE FOOD SAMPLES

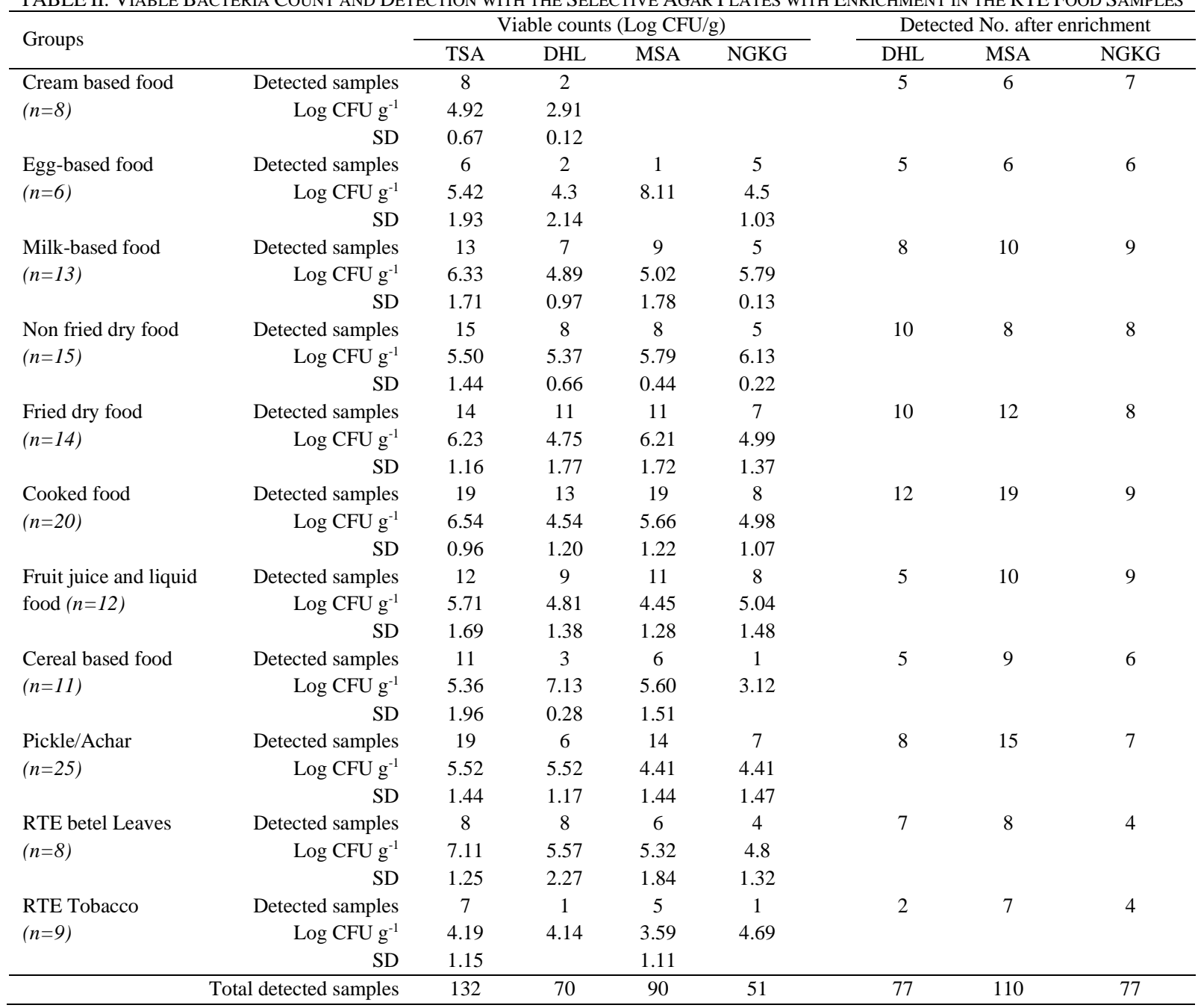

\section{Identification of Selected Strains}

In the case of isolates from DHL and NGKG agar plates, strains that showed NCZ to at least three classes of antimicrobial agents were selected. In the case of isolates from MS agar plates, bacteria that showed $\mathrm{R}$ to at least three classes of antimicrobial agents, including CFX, were selected. The selected isolates from DHL agar were preliminarily classified using commercial API ID 32E kits (BioMerieux, Marcy-I'Etoile, France) for bacterial identification according to the manufacturer's instructions, and the data were analysed with apiweb ${ }^{\mathrm{TM}}$ (https://apiweb.biomerieux.com/). Among that, 11 isolates that showed resistance to the largest having number of the antibiotics were identified based on their 16S rRNA gene sequences. Following the amplification of the 16S rRNA genes using the PCR primers $27 \mathrm{~F}$ and 1492R, the PCR products were sequenced by Macrogen Japan Corp. (Tokyo, Japan). The homology search was performed using BLASTn, which was from the DNA Data Bank of Japan (http://ddbj.nig.ac.jp/blast/blastn).

\section{RESULTS AND DISCUSSION}

\section{A. Values of pH, Salinity, and Total Aerobic Plate Counts of RTE Food Samples}

About the total 141 RTE food samples sold by street vendors in Bangladesh, the average $\mathrm{pH}$ of the $11 \mathrm{RTE}$ food groups ranged from 3.86 to 7.98 (Table I). Zit and kuber (RTE tobacco) had the highest $\mathrm{pH}$ (9.80 and 9.70, respectively, Table II), whereas the lowest $\mathrm{pH}$ (3.86) was observed in the RTE pickle group. The groups' salinity ranged from $0.53 \%$ to $1.86 \%$, and the highest salinity $(2.3 \%)$ was observed in borhani (fermented milk).

In this study, the average total aerobic plate counts (APCs) with TS agar plate of the RTE food groups ranged from 4.19 to $7.11 \log$ CFU/g (Table II). Among the sample APCs, APCs for $6.4 \%$ (9/141) were <2 $\log \mathrm{CFU} / \mathrm{g}, 16 \%$ (22/141) ranged from 2 to $4 \log \mathrm{CFU} / \mathrm{g} 38 \%$ (53/141) ranged from 4 to $6 \log$ $\mathrm{CFU} / \mathrm{g}$, and $40 \%(57 / 141)$ were $>6 \log \mathrm{CFU} / \mathrm{g}$. The bacterial load of RTE betel leaf (7.11 log CFU/g) was the highest among the 11 types of RTE foods. However, several samples of other sample groups, such as egg-alor chop, lassi, borhani, sandesh (milk-based sweet), samosa, chicken roll, crab jhal (curry taste), and basil seed juice, showed a high APC (>8 log $\mathrm{CFU} / \mathrm{g}$ ).

\section{B. Antibiotic Resistance of Isolates}

As summarised in Fig. 1A (raw data is shown in Table III), all 111 isolates formed $\mathrm{NCZ}$ in the presence of VCM, whereas $49 \%, 14 \%$, and $9.0 \%$ of isolates formed $\mathrm{NCZ}$ in the presence of ABPC, FOM, TC, and ST, respectively. Resistance was most commonly observed in FOM (45\%) and ABPC (23\%). Furthermore, 34\%, 18\%, 17\%, 14\%, and $11 \%$ of isolates showed IR to GM, CP, CPFX, ABPC, and FOM, respectively. Among the isolates, 15, 4, and 1 were resistant 
to three, four, and five antibiotics, respectively, as indicated by NCZ formation (Fig. 1B). Origin samples and the 20 isolates showing NCZ against three and more antibiotics are summarised in Table III. There was no correlation between the resistance and RTE food materials and sampling areas.
Preliminary classified names using API ID 32E kit are also shown in Table III. Seven, three, two, two, two, and two isolates were estimated as Enterobacter spp., Klebsiella spp., Escherichia coli, Citrobacter spp., Enterobacteriaceae spp., and Pseudomonas spp., respectively.

\section{A: Isolates from DHL agar}

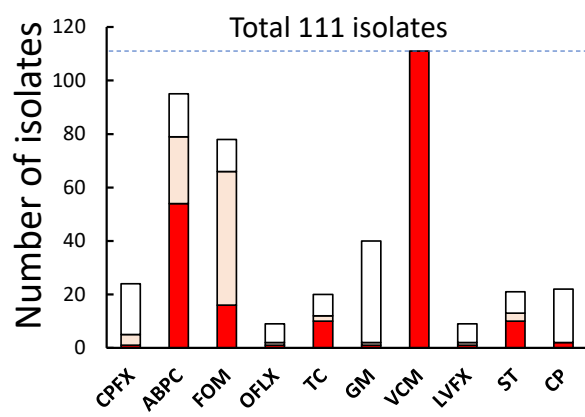

C: Isolates from MS agar

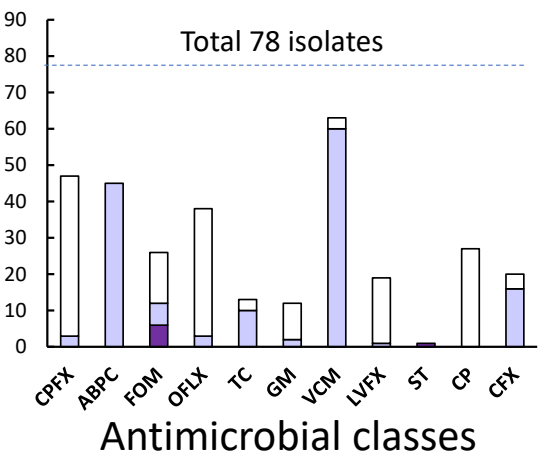

E: Isolates from NGKG agar

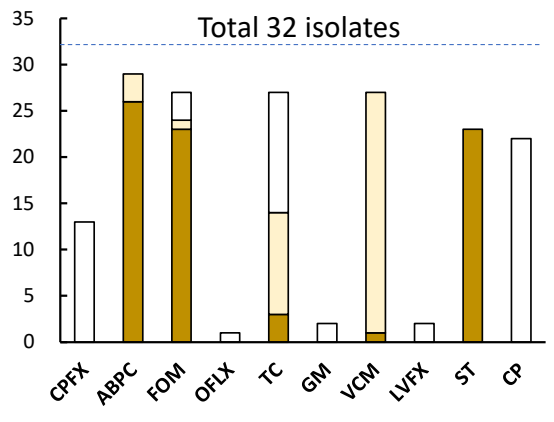

B: Isolates from DHL agar

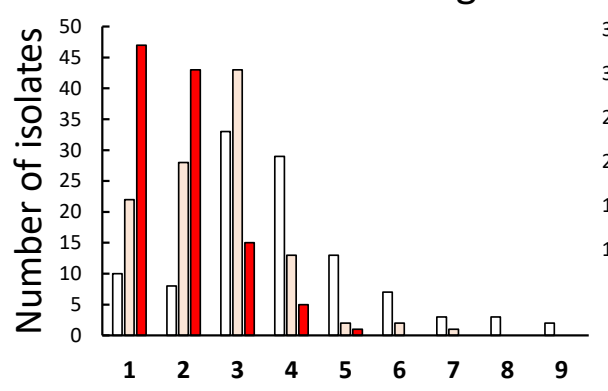

D: Isolates from MS agar

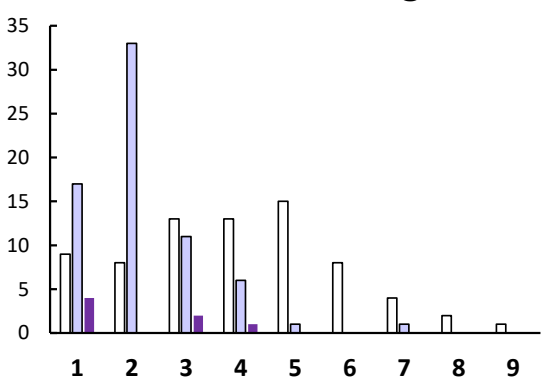

F: Isolates from NGKG agar

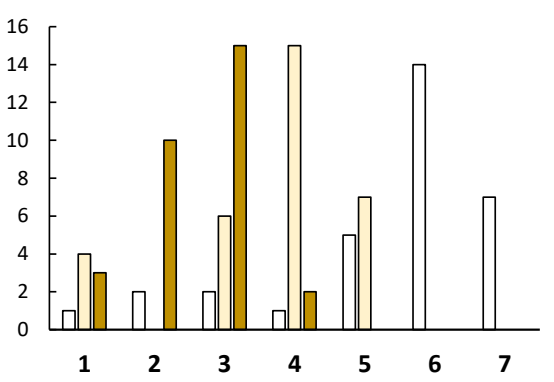

Number of antibiotics shown to be resistant

Fig. 1. Numbers of isolates from DHL agar (A, B), mannitol salt (MS) agar (C, D), and NGKG agar (E, F) plates showing no clear zone (NCZ: closed column), resistance (R: semi-closed column), and intermediate resistance (IR: open column) against antibiotics. CPFX: ciprofloxacin, ABPC: ampicillin, FOM: fosfomycin, OFLX: ofloxacin, TC: tetracycline, GM: gentamicin, VCM: vancomycin, LVFX: levofloxacin, ST: trimethoprim-sulfamethoxazole, CP: chloramphenicol, CFX: cefoxitin.

TABLE III: ISOlATES FROM DHL AgAR PLATES SHOWING NO ClEAR ZONE (NCZ) AGAINST THREE OR MORE DRUGS

\begin{tabular}{|c|c|c|c|c|c|c|}
\hline \multirow{2}{*}{ Groups } & \multicolumn{2}{|l|}{ Sample } & \multirow{2}{*}{$\begin{array}{c}\text { Strain } \\
\text { ID }\end{array}$} & \multirow{2}{*}{ No clear zone to* } & \multirow{2}{*}{ Resistant to* } & \multirow{2}{*}{$\begin{array}{l}\text { Classified names with } \\
\text { API 32E }\end{array}$} \\
\hline & Name & Area & & & & \\
\hline \multirow[t]{4}{*}{ Milk-based food } & Borhani & Dhaka & E-27 & ABPC, TC, VCM & FOM & Enterobacter cloacae \\
\hline & Borhani & Dhaka & E-28 & ABPC, TC, VCM & FOM & Enterobacter aerogenes \\
\hline & Mattha & & E-21 & ABPC, FOM, VCM & & Cronobacter malonaticus \\
\hline & Doi-fuska & Chittagong & E-29 & ABPC, FOM, VCM, ST & FOM, TC & Pseudomonas aeruginosa \\
\hline \multirow[t]{2}{*}{ Non fried dry food } & Vapa pitha-2 & Cox'sbazar & E-40 & ABPC, TC, VCM & FOM & Escherichia coli \\
\hline & Vapa pitha-4 & Cox'sbazar & E-41 & $\mathrm{ABPC}, \mathrm{TC}, \mathrm{VCM}$ & FOM & Klebsiella pneumoniae \\
\hline \multirow[t]{4}{*}{ Fried dry food } & Samosa-1 & Chittagong & E-55 & ABPC, FOM, VCM & CPFX & Enterobacter aerogenes \\
\hline & Samosa-2 & Dhaka & E-47 & ABPC, FOM, VCM & & Enterobacter aerogenes \\
\hline & Nimki & Dhaka & E-53 & ABPC, FOM, VCM & $\mathrm{TC}$ & Salmonella Typhimurium \\
\hline & Velpuri-1 & Dhaka & E-49 & ABPC, FOM, VCM & & Burkholderia cepacian \\
\hline \multirow[t]{2}{*}{ Cooked food } & Fuska-1 & Chittagong & E-51 & ABPC, FOM, VCM, ST, CP & & Pseudomonas aeruginosa \\
\hline & Chotpoti-3 & Dhaka & E-65 & ABPC, TC, VCM, ST & CPFX, FOM & Klebsiella pneumoniae \\
\hline \multirow[t]{2}{*}{$\begin{array}{l}\text { Fruit juice and } \\
\text { liquid food }\end{array}$} & $\begin{array}{l}\text { Basil seed } \\
\text { juice-1 }\end{array}$ & Chittagong & E-35 & ABPC, VCM, ST & & Hafnia alvei \\
\hline & Fuska tok-1 & Chittagong & E-79 & ABPC, TC, VCM, ST & & Citrobacter farmer \\
\hline \multirow[t]{2}{*}{ Cereal based food } & Jhal muri-1 & Chittagong & E-72 & ABPC, FOM, VCM & & Enterobacter aerogenes \\
\hline & Jhal muri-3 & Dhaka & E-104 & ABPC, FOM, VCM & & Raoultella planticola \\
\hline \multirow[t]{2}{*}{ Pickle/Achar } & Guava pickle & Cox'sbazar & E-84 & ABPC, TC, VCM, ST & CPFX, OFLX, LVFX & Citrobacter braakii \\
\hline & Jam pickle-1 & Chittagong & E-42 & ABPC, TC, VCM & & Klebsiella pneumoniae \\
\hline RTE Leaves & Paan-1 & Chittagong & E-30 & ABPC, VCM, ST & & Escherichia coli \\
\hline RTE Tobacco & Paan masala-2 & Chittagong & E-82 & ABPC, FOM, VCM & & Enterobacter cloacae \\
\hline
\end{tabular}

* CFFX: Ciprofloxacin, ABPC: Ampicillin, FOM: Fosfomycin, OFLX: Ofloxacin, TC: Tetracycline, GM: Gentamicin, VCM: Vancomycin, LVFX: Levofloxacin, ST: Trimethoprim-sulfamethoxazole, CP: Chloramphenicol. 
Based on direct detection analysis, 64\% (90/141) of samples were contaminated with Stahphylococcaceae-like bacteria, including 18\% (26/141) with between 2 and $4 \log$ $\mathrm{CFU} / \mathrm{g}$, and 19\% (27/141) with $>6 \mathrm{log} \mathrm{CFU} / \mathrm{g}$ (Table II). Notably, the counts in egg-alor chop and one samosa were higher than $8 \log \mathrm{CFU} / \mathrm{g}$. With the enrichment culture, $78 \%$ $(110 / 141)$ of the tested samples were positive for Staphylococcaceae-like bacteria. As shown in Fig. 1C and Table IV, more than $70 \%$ of Staphylococcaceae-like isolates were susceptible to seven antimicrobials, including SXT, GM, TC, LVFX, CFX, CP, and FOM. Resistance was most commonly observed to VM (59 isolates, 75\%), ABPC (46 isolates, 58\%), CFX (12 isolates, 15\%), TC (11 isolates, $14 \%$ ), and FOM (6 isolates, $8 \%$ ). NCZ formation in the presence of FOM was observed for 7 isolates, 16 of 79 isolates were resistant to at least 3 different classes of antimicrobials, and 7 isolates $(8.8 \%)$ were resistant to more than 4 antimicrobials (Fig. 1D). Origin samples and the selected 15 isolates showed apparent $\mathrm{R}$ against three and more antibiotics, including CFX, summarised in Table IV. There was no correlation between the resistance and RTE food materials and sampling areas. Strain S-54 showed R against the most (seven) of the antibiotics. As shown in Table II, based on direct detection analysis, 36\% (52/141) of samples were contaminated with bacteria detected on NGKG agar, including 9.9\% (14/141) with counts between 2 and 4 $\log \mathrm{CFU} / \mathrm{g}$, and $6.4 \%(9 / 141)$ with counts $>6 \mathrm{log} \mathrm{CFU} / \mathrm{g}$. After enriching the 141 food samples, $55 \%$ (77/141) of samples showed presence of bacteria that grew on NGKG agar. From the NGKG agar plates, a total of 32 typical $B$. cereus-like morphological (White turbid colony and red discoloration of the medium) colonies were selected and isolated. Of these, $81 \%, 72 \%$, and $69 \%$ formed NCZs in the presence of ABPC, ST, and FOM, respectively (Fig. 1E and Table IV). Fifteen isolates $(48.4 \%)$ resistant to three antibiotics and one isolate $(3.2 \%)$ resistant to four antibiotics formed NCZs and were considered MDR (Fig. 1F). Origin samples and the selected 17 isolates showing NCZ against three and more antibiotics are summarised in Table IV. There was no correlation between the resistance and RTE food materials and sampling areas. Besides one strain (B-6), most strains were observed as gram-positive rods with spores. Strain B-19 showed NCZ with four antimicrobial drugs.

One of the most critical aspects of food safety is the emergence of antimicrobial-resistant bacterial strains [21]. Resistant strains are capable of horizontal transfer of resistance genes from environmental and animal food sources to normal human indigenous microbiome and pathogens through the food chain [22], [23]. VCM is regarded as a drug for gram-positive bacteria as it cannot penetrate their outer membrane of gram-negative bacteria [24]. In this study, all isolates from DHL agar (mainly Enterobacteriaceae) showed NCZ with VCM (Fig. 1A). Most of the isolates from MS and NGKG showed clear "R" against VCM (Fig. 1C and E). Furthermore, VCM has been regarded as a silver bullet against MDR gram-positive bacteria; however, issues with VCM-resistant gram-positive bacteria, not only enterococci but also Staphylococcus aureus, have been reported [25].

In this study, most isolates from NGKG agar and a proportion of isolates from DHL agar showed NCZ with ABPC, FOM, and ST (Fig. 1A and E). Resistances of Bacillus spp. against these antibiotics has previously been reported [26]. Additionally, an increase in ampicillin-resistant Enterobacteriaceae is regarded as an alarming issue. Of note, adverse effects of ampicillin dosage on ampicillin resistance in Enterobacteriaceae in swine faeces were reported [27]. Moreover, 16/78 isolates from MS agar showed CFX resistance (Fig. 1C). CFX resistance is regarded as a surrogate marker for detecting methicillin-resistant Staphylococcus aureus [28]. The present study's results suggest that antibiotic-resistant bacteria are ubiquitous in RTE foods distributed in Bangladesh.

\section{Identification of Selected Strains with $16 S$ rRNA Gene Sequencing}

Finally, six, three, and one typical and selected MDR isolates from DHL (E-6, 29, 51, 65, 79, and 84 in Table III), MS (S-3, 54 and 57 in Table IV), and NGKG (B-19 in Table IV) agar plates, respectively, were subjected to $16 \mathrm{~S}$ rRNA gene sequencing to confirm the results. The selected isolates from DHL were identified as four Enterobacteriaceae species - Klebsiella pneumoniae subsp. pneumoniae (E-65, Accession number: LC572262), Enterobacter cloacae (E-79, LC572263), Citrobacter braakii (E-84, LC572264) and Serratia marcescens (E-29, LC572258) - and two species of Pseudomonas: P. plecoglossicida (E-6, LC572260) and $P$. nitroreducens (E-51, LC572261). Three isolates from MS agar having resistance to CFX and three other antibiotics were identified as two Staphylococcus species - S. gallinarum (S-3, LC572265) and S. sciuri (S-54, LC572267) - and Aerococcus viridans (S-57, LC572266). The rRNA sequence of a strain isolated from NGKG (B-19, LC572259) was similar $(99.7 \%)$ to those of several species of B. cereuslike bacteria. With $16 \mathrm{~S}$ rDNA and BLASTn search, four MDR Enterobacteriaceae isolates in this study were identified as K. pneumoniae, E. cloacae, C. braakii, and $S$. marcenses. These were reported as indigenous bacteria and opportunistic virulent bacteria in pneumoniae, bacteraemia, and other infections [29]. The correlation of the virulence and antibiotic-resistant properties is essential for the therapy, though the interplay between resistance and virulence is not understood well [30]. There are reports on antibiotic resistance of $P$. plecoglossicida and $P$. nitroreducens in aquaculture, wastewater, sludge, and soils [31]. The excretion of antibiotics into these environments and the consequent development of resistance are regarded as a major issue in the food supply. The MDR S. gallinarum and S. sciuri were detected in both farms and hospitals, and their susceptibility against drugs, including CFX, varies [32]. Furthermore, $B$. cereus and the related species have been isolated from RTE foods [33].

The current study indicates the poor microbiological quality of several RTE food types and food products prepared by vendors and sold in open markets or supermarkets in Bangladesh. Some of the bacterial species isolated as MDR in the present study and related species have been reported as pathogenic bacteria; however, most isolated bacteria have no virulence. However, as mentioned earlier, horizontal gene transfer of antibiotic resistance to pathogenic bacteria is possible. The present study's results suggest that additional safety measures and regulations are necessary for the preparation and manufacture of RTE foods to ensure food 
quality and safety. Genetic analyses of multi-drug resistance of the selected strains by whole genome sequencing are in progress.

\begin{tabular}{|c|c|c|c|c|c|c|}
\hline \multirow{2}{*}{$\begin{array}{l}\text { Isolated } \\
\text { from }\end{array}$} & \multirow{2}{*}{ Groups } & \multicolumn{2}{|l|}{ Sample } & \multirow{2}{*}{$\begin{array}{l}\text { Strain } \\
\text { ID }\end{array}$} & \multirow{2}{*}{ No clear zone to* } & \multirow{2}{*}{ Resistant to* } \\
\hline & & Name & Area & & & \\
\hline \multirow[t]{15}{*}{ MS agar } & Cream based food & Cream bun- 2 & Dhaka & S-3 & FOM & CPFX,ABPC, VCM, CFX \\
\hline & Egg-based food & Egg-Alor chop & Dhaka & S-9 & & ABPC, FOM, OFLX, VCM, CFX \\
\hline & Milk-based food & Sweet dahi & Chittagong & S-15 & & ABPC, FOM, VCM, CFX \\
\hline & Non fried dry food & Vapa pitha-3 & Chittagong & S-27 & & ABPC, FOM, VCM, CFX \\
\hline & & Patishapta pitha-2 & Dhaka & S-30 & & FOM, TC, VCM, CFX \\
\hline & Fried dry food & Egg chop & Dhaka & S-43 & & FOM, VCM, CFX \\
\hline & & Anthon & Dhaka & S-44 & & FOM, VCM, CFX \\
\hline & Cooked food & Suji/Halwa-2 & Dhaka & S-46 & FOM & ABPC, VCM, CFX \\
\hline & & Fuska-1 & Chittagong & S-47 & FOM & $\mathrm{ABPC}, \mathrm{VCM}, \mathrm{CFX}$ \\
\hline & & Fuska-3 & Dhaka & S-49 & FOM & VCM, CFX \\
\hline & & Chicken roll-1 & Dhaka & S-52 & FOM & VCM, CFX \\
\hline & & Chotpoti-1 & Chittagong & S-57 & FOM & $\mathrm{ABPC}, \mathrm{VCM}, \mathrm{CFX}$ \\
\hline & Fruit juice and liquid food & Shorbath & Cox'sbazar & $S-50$ & FOM & $\mathrm{ABPC}, \mathrm{VCM}, \mathrm{CFX}$ \\
\hline & Cereal based food & Jhal muri-3 & Dhaka & S-62 & & ABPC, FOM, VCM, CFX \\
\hline & RTE Leaves & Paan-2 & Cox'sbazar & S-54 & ST & CPFX,OFLX, GM, VCM, LVFX \\
\hline \multirow{17}{*}{$\begin{array}{l}\text { NGKG } \\
\text { agar }\end{array}$} & Egg-based food & Egg Cake-2 & Dhaka & B-3 & ABPC, FOM, ST & $\mathrm{TC}, \mathrm{VCM}$ \\
\hline & & Egg-Alor chop & Dhaka & B-6 & ABPC, FOM, TC, ST & VCM \\
\hline & Milk-based food & Lassi & Chittagong & B-7 & ABPC, FOM, ST & VCM \\
\hline & Non fried dry food & Vapa pitha-2 & Cox'sbazar & B-10 & ABPC, FOM, ST & TC, VCM \\
\hline & & Vapa pitha-4 & Cox'sbazar & B-11 & ABPC, FOM, ST & TC, VCM \\
\hline & & Chitoi pitha & Cox'sbazar & B-12 & ABPC, FOM, ST & $\mathrm{TC}, \mathrm{VCM}$ \\
\hline & & Patishapta pitha-2 & Dhaka & B-13 & ABPC, FOM, ST & VCM \\
\hline & Fried dry food & Samosa-2 & Dhaka & B-17 & ABPC, FOM, ST & VCM \\
\hline & & Anthon & Dhaka & B-18 & ABPC, FOM, VCM & $\mathrm{TC}$ \\
\hline & Cooked food & Fuska-3 & Dhaka & B-19 & ABPC, FOM, ST, TC & \\
\hline & & Chicken roll-2 & Chittagong & B-21 & ABPC, FOM, ST & VCM \\
\hline & & Chotpoti-3 & Dhaka & B-22 & ABPC, FOM, ST & TC, VCM \\
\hline & Fruit juice and liquid food & Basil seed juice-1 & Chittagong & B-23 & ABPC, FOM, ST & VCM \\
\hline & & Aloe vera juice & Chittagong & B-28 & ABPC, FOM, ST & VCM \\
\hline & & Sugarcane juice- 2 & Dhaka & B-29 & ABPC, FOM, ST & VCM \\
\hline & Cereal based food & Jhal muri-1 & Chittagong & B-30 & ABPC, FOM, ST & VCM \\
\hline & RTE Tobacco & Pan masala-2 & Chittagong & B-31 & ABPC, FOM, ST & TC, VCM \\
\hline
\end{tabular}

* CFFX: Ciprofloxacin, ABPC: Ampicillin, FOM: Fosfomycin, OFLX: Ofloxacin, TC: Tetracycline, GM: Gentamicin, VCM: Vancomycin, LVFX:

Levofloxacin, ST: Trimethoprim-sulfamethoxazole, CP: Chloramphenicol, CFX: Cefoxitin

\section{CONFLICT OF INTEREST}

No conflict of interest declared.

\section{REFERENCES}

[1] Muzaffar AT, Huq I, Mallik BA. Entrepreneurs of the streets: an analytical work on the street food vendors of Dhaka city. Int $J$ Bus Manag. 2009; 4: 80-88.

[2] Khairuzzaman M. Chowdhury FM, Zaman S, Mamun, AA, Bari ML. Food safety challenges towards safe, healthy, and nutritious street foods in Bangladesh- a review. Int J Food Sci. 2014; 483519.

[3] Banik A, Abony M, Datta S, Towhid S. Microbiological quality of ready-to-eat food from Dhaka, Bangladesh. Curr Res Nutr Food Sci. 2019; 7: 161-168.

[4] Rahman MM, Rahman MH, Ansary, NP. Safety issues of street foods in Bangladesh. Time J Biol Sci Technol. 2014; 2: 21-32.

[5] Mamun MA, Rahman MM, Turin TC. Microbiological quality of selected street food items vended by school-based street food vendors in Dhaka, Bangladesh. Int J Food Microbiol. 2013; 166: 413-418.

[6] Noor R. Feroz FN. Microbiological quality of commonly consumed street foods in Bangladesh. Nutr Food Sci. 2016; 46: 130-141.

[7] Das SK, Ahmed S, Ferdous F, Farzana FD, Chisti MJ, Latham JR, et al. Etiological diversity of diarrheal disease in Bangladesh. J Infect Dev Countries. 2013; 7: 900-909.

[8] Nyenje ME, Odjadjare CE, Tanih NF, Green E, Ndip RN. Food borne pathogens recovered from ready-to-eat foods from roadside cafeterias and retail outlets in Alice, Eastern Cape Province, South Africa: Public health implications. Int J Environ Res Pub Health. 2012; 9: 2608-2619.
[9] Fernandez-Segovia I, Perez-Llacer A, Peidro B, Fuentes A Implementation of food safety management systems according to ISO 22000 in the food supplement industry: A case study. Food Control. 2014; 43: 28-34.

[10] Banik A, Abony M, Datta S. Microbial status and multidrug resistance pattern of pathogenic bacteria isolated from street food in Dhaka city, Bangladesh. J Adv Microbiol. 2018; 13: 1-13.

[11] Girona-Alarcón M, Fresánm E, Garcia-Garcia A, Perez SB, Grgallo $\mathrm{MB}$, Villalobos AF, et al. Device-associated multidrug-resistan bacteria surveillance in critically ill children: 10 years of experience. Acta Paediatrca. 2021; 110: 203-209.

[12] Wang HH, Manuzon M, Lehman M, Wan K, Luo H, Wittum TE, et al Food commensal microbes as a potentially important avenue in transmitting antibiotic resistance genes. FEMS Microbiol Lett. 2006 254: $226-231$

[13] Li Y, Cao W, Liang S, Yamasaki S, Chen X, Shi L, et al. (2020) Metagenomic characterization of bacterial community and antibiotic resistance genes in representative ready-to-eat food in southern China. Sci Rep. 2020; 10: 15175.

[14] Campos J, Gil J, Mourão J, Peixe L, Antunes P. Ready-to-eat streetvended food as a potential vehicle of bacterial pathogens and antimicrobial resistance: An exploratory study in Porto region, Portugal. Int J Food Microbiol. 2015; 206; 1-6.

[15] Gormley FJ, Little CL, Grant KA, de Pinna E, McLauchilin J. The microbiological safety of ready-to-eat specialty meats from markets and specialty food shops: a UK wide study with a focus on Salmonella and Listeria. Food Microbiol. 2010; 17: 243-249.

[16] Oliveira MA, de Souza VM, Bergamini AMA, De Martinis ECP Microbiological quality of ready-to-eat minimally processed vegetables consumed in Brazil. Food Control. 2011; 22: 1400-1403. 
[17] Aydin A, Muratoglu K, Sudagidan M, Bostan K, Okuklu B, Harsa S. Prevalence and antibiotic resistance of food borne Staphylococcus aureus isolates in Turkey. Foodborne Pathog Dis. 2010; 8: 63-69.

[18] Zurfluh K, Nüesch-Inderbinen MT, Morach A, Berner AZ, Hächler H, Stephan R. Extended-spectrum- $\beta$-lactamase-producing Enterobacteriaceae isolated from vegetables imported from the Dominican Republic, India, Thailand, and Vietnam. Appl Environ Microbiol. 2015; 81: 3115-3120.

[19] Happy A, Alam M, Mahmud S, Imran S, Rony MH, Azim M, et al. Isolation, identification and characterization of gram-negative bacteria from popular street food (chotpoti) at Savar area, Dhaka, Bangladesh. Open Access Library J. 2018; 5: 1-11.

[20] British Society for Antimicrobial Chemotherapy. BSAC Methods for Antimicrobial Susceptibility Testing. Version 14. 2015.

[21] Girona-Alarcón M, Fresánm E, Garcia-Garcia A, Perez SB, Grgallo $\mathrm{MB}$, Villalobos AF, et al. Device-associated multidrug-resistant bacteria surveillance in critically ill children: 10 years of experience. Acta Paediatrca. 2021; 110: 203-209.

[22] Ahmed AM, Shimamoto T. Molecular characterization of multidrug resistant Shigella spp. of food origin. Int J Food Microbiol. 2015: 194 78-82

[23] Mclnnes RS, MacCallum GE, Lamberte LE, van Schaik W. Horizontal transfer of antibiotic resistance genes in the human gut microbiome. Curr Opin Microbiol. 2020; 53: 35-43.

[24] Kaur A, Preet S, Kumar V, Kumar R, Kumar R. Synergetic effect of vancomycin loaded silver nanoparticles for enhanced antibacterial activity. Colloids Surfaces B: Biointerfaces. 2019; 176: 62-69.

[25] Cong Y, Yang S, Rao X. (2020) Vancomycin resistant Staphylococcus aureus infections: A review of case updating and clinical features. $J$ Adv Res. 2020; 21: 169-176.

[26] Luna VA, King DS, Gulledge J, Cannons AC, Amuso PT, Cattani J. Susceptibility of Bacillus anthracis, Bacillus cereus, Bacillus mycoides, Bacillus pseudomycoides and Bacillus thuringiensis to 24 antimicrobials using Sensititre automated microbroth dilution and Etest agar gradient diffusion methods. J Antimicrob Chemother. 2007; 60: 555-567.

[27] Bibbal D, Dupouy V, Ferré JP., Bousquet-Mélou A. Impact of three ampicillin dosage regimens on selection of ampicillin resistance in Enterobacteriaceae and excretion of blaTEM genes in swine feces. Appl Environ Microbiol. 2007; 73: 4785-4790.

[28] Fernandes CJ, Fernandes LA, Collignon P. Cefoxitin resistance as a surrogate marker for the detection of methicillin-resistan Staphylococcus aureus. J Antimicrob Chemother. 2005; 55: 506-510.

[29] Tzouvelekis LS, Markogiannakis A, Psichogiou M, Tassios PT, Daikos GL. Carbapenemases in Klebsiella pneumoniae and other Enterobacteriaceae: an evolving crisis of global dimensions. Clin Microbiol Rev. 2012; 25: 682-707.

[30] Hennequin C, Robin F. Correlation between antimicrobial resistance and virulence in Klebsiella pneumoniae. Eur J Clin Microbiol Infect Dis. 2016; 35: 333-341.

[31] Tsutsui H, Anami Y, Matsuda M, Inoue D, Sei K, Soda S. Transfer of plasmid pJP4 from Escherichia coli and Pseudomonas putida to bacteria in activated sludge developed under different sludge retention times. J Biosci Bioeng. 2010; 110: 684-689.

[32] Ouoba LIL, Mbozo ABV, Anyogu A, Obioha PI, Lingani-Sawadogo $\mathrm{H}$, Sutherland JP, et al. Environmental heterogeneity of Staphylococcus species from alkaline fermented foods and associated toxins and antimicrobial resistance genetic elements. Int J Food Microbiol. 2019; 311: 108356

[33] Rosenquist H, Smidt L, Ansersen SR, Jensen GB, Wilcks A, Notes A. Occurrence and significance of Bacillus cereus and Bacillus thuringiensis in ready-to-eat food. FEMS Microbiol Lett. 2005; 250: $129-136$

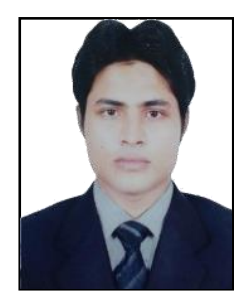

Sayed M. Nahidul-Islam, date of birth 16/08/1990, place of birth: Cox'sbazar, Bangladesh, obtained his MS in Microbiology (2014) and BSc in Microbiology (2013) from University of Chittagong, Bangladesh. He also completed his second master's degree in Food Science and Technology (2019) from Tokyo University of Marine Science and Technology, Japan. He is currently working as $\mathrm{PhD}$ student in the Department of Food Science and Technology, Tokyo University of Marine Science and Technology, Japan. His research interests include food microbiology, food safety, and public health. 